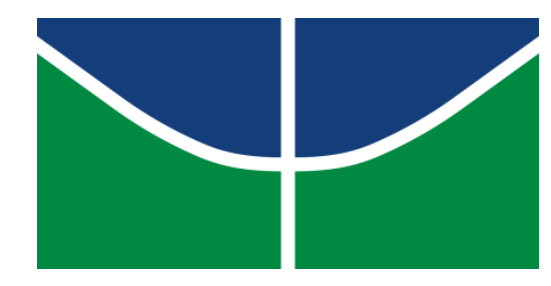

UNIVERSIDADE DE BRASÍLIA

FACULDADE DE AGRONOMIA E MEDICINA VETERINÁRIA

PEDRO SÉRGIO REIS MOURA

EFEITO DE ADJUVANTE E ASSISTÊNCIA DE AR NA BARRA NO ESPECTRO DE GOTAS DE PULVERIZAÇÃO NO TERÇO INFERIOR DA CULTURA DA SOJA

BRASÍLIA, DF

2019 


\title{
EFEITO DE ADJUVANTE E ASSISTÊNCIA DE AR NA BARRA NO ESPECTRO DE GOTAS DE PULVERIZAÇÃO NO TERÇO INFERIOR DA CULTURA DA SOJA
}

\begin{abstract}
Monografia apresentada à Faculdade de Agronomia e Medicina Veterinária - FAV da Universidade de Brasília - UnB, como parte das exigências do curso de Graduação em Agronomia, para a obtenção do título de Engenheiro Agrônomo.
\end{abstract}

Orientador: Prof. Dr. Tiago Pereira da Silva Correia

BRASÍLIA, DF 
MOURA, Pedro Sérgio Reis.

“EFEITO DE ADJUVANTE E ASSISTÊNCIA DE AR NA BARRA NO ESPECTRO DE GOTAS DE PULVERIZAÇÃO NO TERÇO INFERIOR DA CULTURA DA SOJA". Orientação Tiago Pereira da Silva Correia, Brasília 2019. 39p. Monografia graduação (G) - Universidade de Brasília/ Faculdade de Agronomia e Medicina Veterinária, 2019.

1. Glycine $\max$ L. 2. Corbetura do alvo 3. Pulverizador 4. Tamanho de gotas 5. Tecnologia de aplicação

\section{REFERÊNCIA BIBLIOGRÁFICA:}

MOURA, P. S. R. EFEITO DE ADJUVANTE E ASSISTÊNCIA DE AR NA BARRA NO ESPECTRO DE GOTAS DE PULVERIZAÇÃO NO TERÇO INFERIOR DA CULTURA DA SOJA. Brasília: Faculdade de Agronomia e Medicina Veterinária, Universidade de Brasília, 39p. 2019. Monografia.

\section{CESSÃO DE DIREITOS:}

Nome do Autor: Pedro Sérgio Reis Moura

Título da Monografia de Conclusão de Curso: Efeito de adjuvante e assistência de ar na barra do pulverizador agrícola no espectro de gotas de pulverização no terço inferior da cultura da soja.

Grau: Graduação. Ano: 2019.

É concedida à Universidade de Brasília permissão para reproduzir cópias desta monografia de graduação e para emprestar ou vender tais cópias somente para fins acadêmicos e/ou científicos. $\mathrm{O}$ autor reserva-se outros direitos de publicação e nenhuma parte desta monografia de graduação pode ser reproduzida sem autorização por escrito do autor.

PEDRO SÉRGIO REIS MOURA

CPF: 047.212.531-17

sergioreispedro@gmail.com 


\section{PEDRO SÉRGIO REIS MOURA}

\section{EFEITO DE ADJUVANTE E ASSISTÊNCIA DE AR NA BARRA NO ESPECTRO DE GOTAS DE PULVERIZAÇÃO NO TERÇO INFERIOR DA CULTURA DA SOJA}

Monografia apresentada à Faculdade de Agronomia e Medicina Veterinária - FAV da Universidade de Brasília - UnB, como parte das exigências do curso de Graduação em Agronomia, para a obtenção do título de Engenheiro Agrônomo.

Orientador: Prof. Dr. Tiago Pereira da Silva Correia

BANCA EXAMINADORA

Prof. Dr. Tiago Pereira da Silva Correia Faculdade de Agronomia e Medicina Veterinária - FAV/UnB

Orientador

Prof. Dr. Francisco Faggion

Faculdade de Agronomia e Medicina Veterinária - FAV/UnB

Examinador

Prof. Dr. Leandro Augusto Felix Tavares

Univ. Federal dos Vales do Jequitinhonha e Mucuri - UFVJM/Campus Unaí-MG

Examinador 


\section{DEDICATÓRIA}

A Deus, por tornar possível aquilo para parecia impossível, dando força, perseverança e saúde, além de sabedoria e paciência. A minha família, por nunca desacreditarem, pelo apoio emocional e financeiro. Ao meu avô Anísio Pedro Dos Reis (In memoriam). 


\section{AGRADECIMENTOS}

A Deus, pelas oportunidades colocadas em minha vida, pelas graças e bençãos, e por ter chegado aonde cheguei.

A minha família, minha avó Nair Cunha dos Reis, pelas orações, pelo colo, pela compreensão e ensinamentos; a minha mãe, Graciana Cunha dos Reis, pelo apoio financeiro, pelo apoio de mãe, pela paciência e entendimento; a minha tia e madrinha, Adriana Cunha dos Reis, pelas palavras, pelas orações e bençãos sobre mim; a meu irmão, Sebastião Theodoro de Moura Neto, pelo apoio durante esses anos.

A minha namorada e companheira, Brenda Maria Silva Campos, que me acompanhou nesses 6 anos de curso, por não me deixar desistir, por acreditar em mim quando tudo parecia perdido, pelo carinho, compreensão e paciência.

Ao meu orientador, Prof. Dr. Tiago Pereira da Silva Correia, pelos ensinamentos, apoio, paciência, e pela oportunidade e honra de realizar e me orientar neste trabalho de conclusão de curso.

Ao LAMAGRI, pelo apoio, auxílio durante o experimento.

A faculdade de Agronomia e Medicina Veterinária da Universidade de Brasília, aos professores do curso de Agronomia pelos ensinamentos passados, pela paciência, ajuda, carinho, e sobre tudo pela amizade. 


\section{RESUMO}

A sojicultura está entre as atividades agrícolas mais difundidas e economicamente importantes para o mercado de commodities mundial. O cultivo de soja enfrenta diversos desafios, principalmente relacionados a problemas fitossanitários com pragas e doenças, exigindo maior precisão e cuidados na operação de pulverização de defensivos agrícolas. Dentre as possibilidades para aumentar a eficiência da pulverização pelo mercado ao produtor estão os adjuvantes e a assistência de ar na barra do pulverizador, produtos cujo o apelo comercial é incrementar a qualidade da aplicação de defensivos. Sendo assim, o objetivo do trabalho foi avaliar o espectro de gotas de pulverização no terço inferior da cultura da soja utilizando calda com e sem adjuvante, e aplicação com e sem assistência de ar na barra do pulverizador tratorizado. O experimento foi realizado a campo na Fazenda Experimental Água Limpa, situada em Brasília-DF pertencente a Universidade de Brasília. O delineamento experimental utilizado foi o inteiramente casualizado, sendo os tratamentos formados por um fatorial 2 x 2 (calda sem e com adjuvante; aplicação sem e com assistência de ar na barra de pulverização) com seis repetições cada. As variáveis avaliadas foram porcentagem de gotas com diâmetro igual ou menor que $100 \mu \mathrm{m}(\% \leq 100 \mu \mathrm{m})$, diâmetro mediano volumétrico de gotas (DMV), amplitude relativa (AR), cobertura e volume depositado de gotas sobre o alvo. Para a coleta das gotas pulverizadas com pulverizador tratorizado de barras foi utilizada a metodologia proposta por Baio et al. (2014), que utiliza corante Xadrez na calda para marcação das gotas depositadas em papel fotográfico. Os papeis foram fixados no terço inferior das plantas de soja no estágio de desenvolvimento R7. Para obtenção dos dados os papeis fotográficos amostrados foram submetidos a análise pelo software Gotas (Embrapa, 2010). Os dados obtidos foram submetidos a análise de variância (ANOVA) e as médias comparadas pelo teste de Turkey ao nível de 5\% de probabilidade. Os resultados indicaram que a aplicação com adjuvante e sem assistência de ar na barra possibilitam um menor número de gotas com diâmetro inferior a $100 \mu \mathrm{m}$. O DMV é maior com adjuvante e não é alterado pela assistência de ar na barra. Menor AR, maior cobertura do alvo e volume aplicado são obtidos pela interação entre calda com adjuvante e aplicação com assistência de ar na barra.

Palavras-chave: Cobertura do alvo, Glycine max L., Pulverizador, Tamanho de gotas, Tecnologia de aplicação 


\begin{abstract}
Soybean farming is among the most widespread and economically important agricultural activities for the world commodity market. Soybean cultivation faces several challenges, mainly related to phytosanitary problems with pests and diseases, requiring greater precision and care when spraying pesticides. Possibilities for increasing market-to-producer spray efficiency include adjuvants and air assist in the spray bar, products whose commercial appeal is to increase the quality of pesticide application. Thus, the objective of this work was to evaluate the spray droplet spectrum in the lower third of soybean crop using syrup with and without adjuvant, and application with and without air assistance on the tractor sprayer boom. The experiment was carried out in the field at Água Limpa Experimental Farm, located in Brasília-DF, belonging to the University of Brasília. The experimental design was completely randomized, and the treatments consisted of a $2 \times 2$ factorial (syrup without and with adjuvant; application without and with air assistance in the spray bar) with six replications each. The variables evaluated were percentage of drops with a diameter equal to or smaller than $100 \mu \mathrm{m}$ $(\% \leq 100 \mu \mathrm{m})$, median volumetric droplet diameter (DMV), relative amplitude (RA), coverage and deposited droplet volume over the target. To collect the drops sprayed with tractor bar sprayer, the methodology proposed by Baio et al. (2014), which uses Chess dye in the syrup to mark the drops deposited on photographic paper. Roles were fixed in the lower third of soybean plants at the R7 development stage. To obtain the data, the sampled photographic papers were analyzed by the Gotas software (Embrapa, 2010). The obtained data were submitted to analysis of variance (ANOVA) and the means compared by the Turkey test at 5\% probability level. The results indicated that the application with adjuvant and without air assistance in the bar allows a smaller number of drops with a diameter of less than $100 \mu \mathrm{m}$. The DMV is higher with adjuvant and is not altered by air assist in the bar. Lower AR, higher target coverage and applied volume are obtained by the interaction between spray adjuvant and air assisted spray application.
\end{abstract}

Keywords: Target Coverage, Glycine max L., Sprayer, Droplet Size, Application Technology 


\section{LISTA DE TABELAS}

Página

Tabela 1. Interação entre o fator calda e aplicação para a variável porcentagem do volume de gotas com diâmetro menor ou igual a $100 \mu \mathrm{m}$ (\% $\leq 100 \mu \mathrm{m})$

Tabela 2. Interação entre o fator calda e aplicação para os resultados de amplitude relativa (AR), do tamanho das gotas

Tabela 3. Interação dos fatores calda e aplicação para a variável cobertura do alvo

Tabela 4. Interação dos fatores calda e aplicação para a variável volume depositado de calda sobre o alvo

\section{LISTA DE FIGURAS}

Página

Figura 1. Croqui da área experimental, com a distribuição das parcelas

Figura 2. Condições meteorológicas durante a realização do ensaio.

Figura 3. Conjunto mecanizado sem assistência de ar na barra do pulverizador.

Figura 4. Conjunto mecanizado com assistência de ar na barra do pulverizador.

Figura 5. Amostra de papel fotográfico marcado com corante preto.

Figura 6. Porcentagem do volume de gotas com diâmetro menor que $100 \mu \mathrm{m}$ $(\% \leq 100 \mu \mathrm{m})$ com e sem adjuvante na calda.

Figura 7. Porcentagem do volume de gotas com diâmetro menor que $100 \mu \mathrm{m}$ $(\% \leq 100 \mu \mathrm{m})$ na aplicação com e sem assistência de ar na barra de pulverização.

Figura 8. Diâmetro mediano volumétrico das gotas (DMV) com e sem adjuvante na calda

Figura 9. Diâmetro mediano volumétrico das gotas (DMV) na aplicação com e sem assistência de ar na barra de pulverização. 


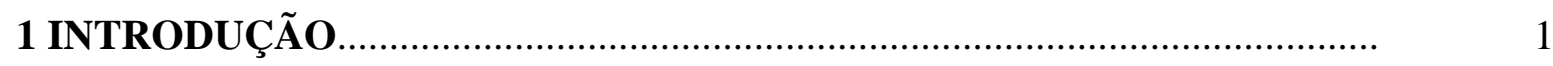

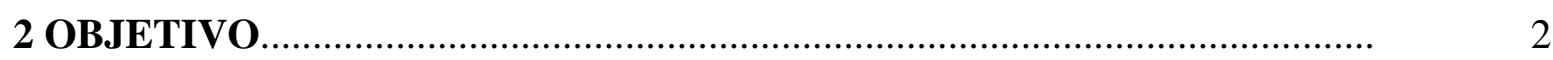

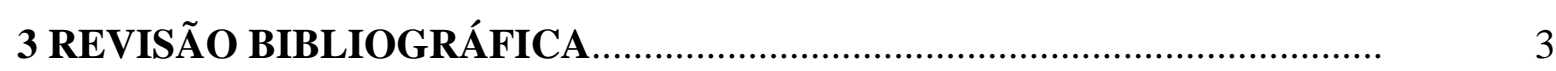

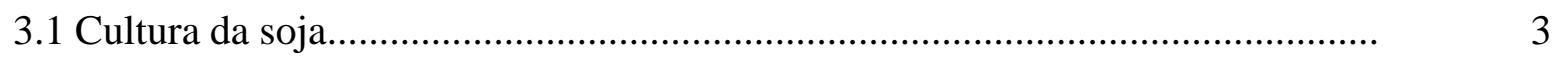

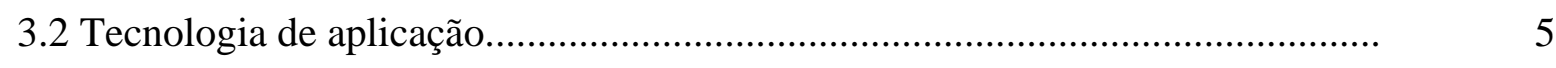

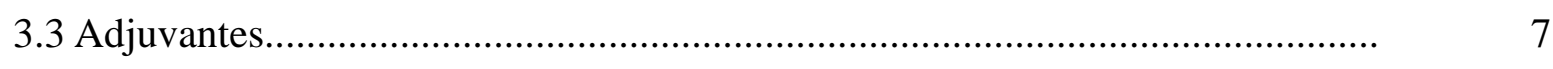

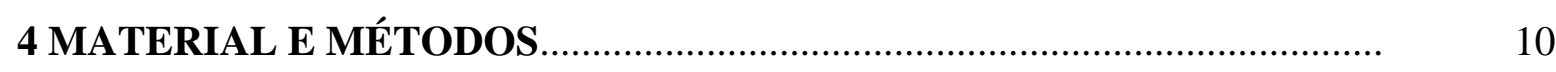

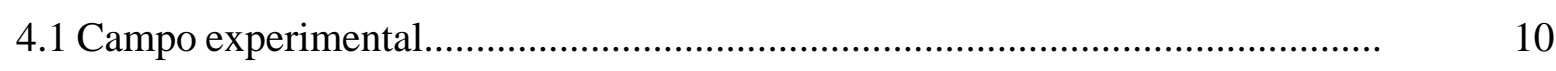

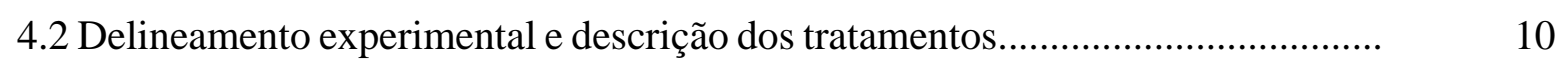

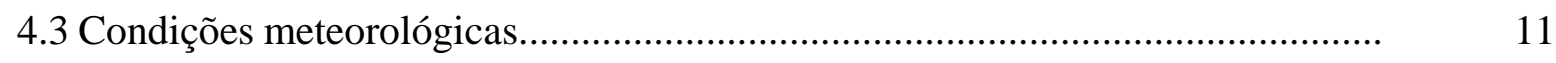

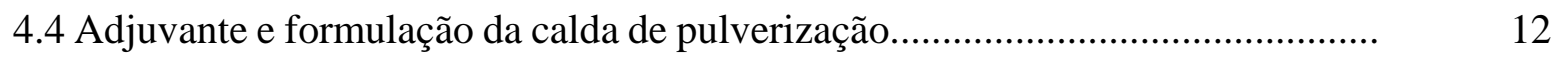

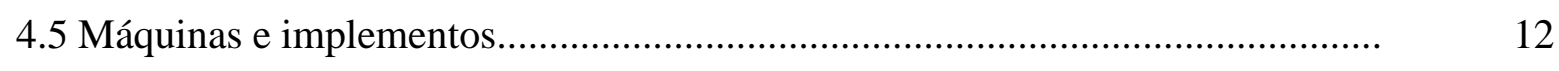

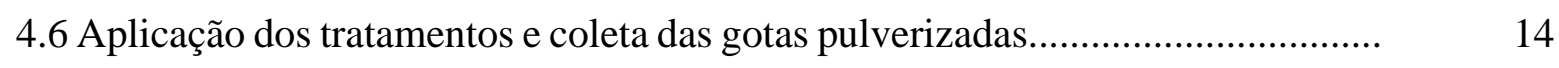

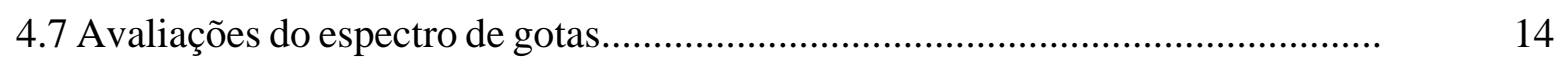

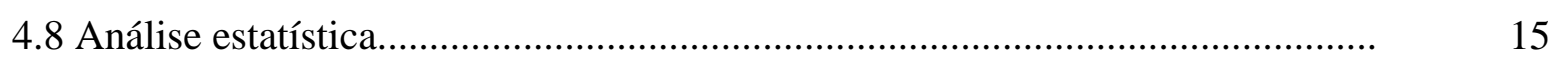

5 RESULTADOS E DISCUSSÃO 16

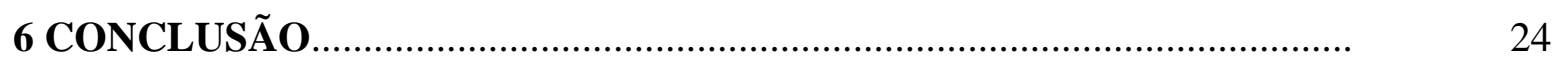

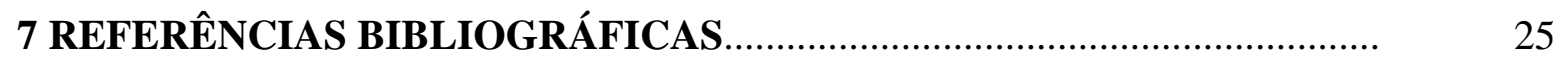




\section{INTRODUÇÃO}

O crescente aumento da população mundial trouxe consigo um grande desafio, produzir mais alimentos de qualidade em um menor tempo para atender as exigências do mercado. $\mathrm{O}$ aumento da produtividade somente é possível utilizando tecnologias e boas práticas agrícolas, desde defensivos agrícolas para controle de pragas e doenças a operações mecanizadas.

Em se tratando da aplicação de defensivos agrícolas é comum que produtores levem em consideração, na maioria das vezes, somente o produto a ser aplicado, deixando a operação de aplicação em segundo plano, sem saber que a eficiência dos produtos depende da correta deposição dele no alvo. A tecnologia de aplicação auxilia nesta tarefa, possibilitando, a partir do conjunto de conhecimentos, aplicações com espectro de gotas adequado, com menor risco de deriva e segurança ambiental.

Um dos problemas práticos da aplicação de defensivos é a dificuldade de fazer as gotas chegarem na parte inferior do alvo, a exemplo as folhas do terço inferior de culturas com massa foliar densa como a soja. Como possibilidade de melhorar essa situação são disponibilizados pelo mercado adjuvantes, pulverizadores com assistência de ar nas barras e outras tecnologias para aplicação.

Tanto adjuvantes como assistência de ar nas barras do pulverizador são fatores que possivelmente influenciam o espectro de gotas, sendo assim, o presente trabalho buscou estudar a influência desses fatores para a aplicação de defensivos agrícolas que atinjam o terço inferior de plantas de soja. 


\section{OBJETIVO}

O objetivo do trabalho foi avaliar o espectro de gotas de pulverização no terço inferior da cultura da soja utilizando calda com e sem adjuvante, e aplicação com e sem assistência de ar na barra do pulverizador. 


\section{REVISÃO BIBLIOGRÁFICA}

\subsection{Cultura da soja}

A soja, Glycine Max (L.) Merrill, é amplamente cultivada no Brasil e no mundo, sendo parte do conjunto de atividades agrícolas com maior importância no mercado mundial de commodities. É pertencente à família das Fabaceas, possui hábito herbáceo e caracteriza-se pela simbiose com bactérias fixadoras de nitrogênio (SEDIYAMA, 2013; CÂMARA, 2015).

Segundo a USDA (2019) e CONAB (2018), o Brasil é o maior produtor mundial do grão com $33 \%$ da produção, seguido dos Estados Unidos com 32,85\% e Argentina 15,80\%. De acordo com os dados da CONAB (2019), na safra 2018/2019 a cultura ocupou aproximadamente 35,8 milhões de hectares, sendo as maiores ocupações nas regiões centrooeste, sul e nordeste respectivamente, com produtividade média nacional de $3.206 \mathrm{~kg} \mathrm{ha}^{-1}$, totalizando uma produção de aproximadamente 114,843 milhões de toneladas.

Segundo Black (2000), a grande importância da cultura encontra-se na transformação industrial dos grãos para extração de óleo, farelo, leite, proteínas e leveduras, utilizados principalmente para alimentação animal e humana, indústria de biocombustíveis, farmacêutica entre outras. O teor de proteína e óleo dos grãos de soja podem ultrapassar 40 e $20 \%$ respectivamente.

Como descrito por Câmara (2000) devido ao sucessivo crescimento da cultura e área cultivada no Brasil, novas doenças e adversidades bióticas surgiram em território nacional. No final dos anos 90 foram diagnosticadas algumas doenças de final de ciclo, como o oídio. Nos anos seguintes nematoides de cisto, e por fim uma das mais importantes, a ferrugem asiática (Phakopsora pachyrhizi). Ainda segundo Câmara (2000), a doença teve o seu primeiro relato de ocorrência na safra 2001/2002, tendo como origem o Paraguai, e por seguinte se alastrou pelos estados brasileiros ao sul, como Paraná e Mato Grosso do Sul. Este fungo é capaz de se multiplicar e disseminar via vento, de forma rápida e por distâncias grandes. Sua característica é de desfolha das plantas, diminuindo a área fotossintética, sendo então uma das doenças mais temidas da soja (PIVONIA \& YANG, 2004). Os sintomas iniciais aparecem na parte axial das folhas, com aproximadamente 4 dias após a infecção do fungo, sendo a liberação dos esporos a partir das pústulas ocorrendo 7 dias após a infecção iniciar (SIKORA et al., 2014). Para seu desenvolvimento, as condições ideais de umidade e temperatura devem estar presentes, sendo 
de 75 a $80 \%$ de UR e temperaturas entre 18 a $26^{\circ} \mathrm{C}$, então em climas de chuvas frequentes, com altos índices de orvalho, são condições propícias para o desenvolvimento do fungo (RUPE; SCONYERS, 2008; SIKORA et al., 2014).

A severidade e incidência da doença é verificada nas fases de fechamento do dossel da planta, no início da floração e na fase inicial reprodutiva (SIKORA et al., 2014). Os sintomas de infecção causados pelo fungo são pontos minúsculos, de no máximo um milímetro de diâmetro, com tom mais escuro do que a folha sadia de coloração esverdeada a cinzaesverdeada (YORINORI et al., 2004).

Para o controle químico da ferrugem, são utilizados dois grupos de químicos, os Triazóis e as Estrobilurinas, ou até mesmo a mistura de produtos destes dois grupos, como por exemplo os azoxystrobin, tebuconazole, flutriazol (MORI \& COSTAMILAN, 2004). Na ausência de controle químico da doença é fatídico grandes prejuízos na produtividade de grãos (SCHERMA et al., 2009).

Segundo Bueno et al. (2011) sobre o controle da ferrugem na soja é dada maior importância aos produtos e menor à forma de aplicação. De acordo com Cunha et al. (2014) a forma de aplicação de defensivos agrícolas deve ser sempre levada em consideração para a obtenção de sucesso no controle de doenças, e a dificuldade a campo ocorre, principalmente, devido a condições ambientais, espectro de gotas e máquinas. $\mathrm{O}$ autor esclarece que a cobertura proporcionada pela aplicação de fungicidas sobre o dossel da soja em geral é pouco uniforme, principalmente na parte inferior, resultando em controle ineficiente, mesmo com produtos sistêmicos.

Segundo Boller et al. (2007), os fungicidas exigem, em geral, boa distribuição ao longo do dossel. Para o sucesso da aplicação é necessário dominar a forma de aplicação, de modo a garantir que o produto alcance o alvo, minimizando as perdas e reduzindo a contaminação do ambiente. Nuyttens et al. (2011), relatam que um dos maiores problemas da agricultura a ser superado é o fato de que, muitas vezes, parte do produto aplicado se perde, principalmente, pela má qualidade da aplicação, seja ela terrestre ou aérea.

Para Yu et al. (2009), o tamanho de gotas e a uniformidade da aplicação são dois parâmetros muito importantes para o controle eficaz de doenças, desse modo a tecnologia de aplicação é uma ferramenta muito importante. Segundo Butzen et al. (2005) a indústria química e de máquinas agrícolas tem trabalhado para o desenvolvimento de novas tecnologias para aplicação, dentre elas, novas pontas de pulverização, barras e uso de adjuvantes. 


\subsection{Tecnologias de aplicação}

De acordo com Ramos \& Pio (2008), os defensivos agrícolas podem ser aplicados de diferentes formas, tais como, via sólida, líquida ou gasosa, sendo a segunda a mais empregada, neste caso utilizando a água como diluente. Tal aplicação pode ser realizada na forma de gotas, sendo a técnica mais utilizada devido a sua multifuncionalidade.

De acordo com Matuo (1998) o princípio básico da tecnologia de aplicação é a divisão do líquido a ser aplicado em gotas, as quais transportam os princípios ativos dos defensivos agrícolas na direção dos alvos. Para tanto, Christofoletti (1999) difere aplicação de pulverização, definindo como pulverização o processo físico-mecânico de formação de um volume líquido (calda) em gotas, e aplicação como sendo o processo de transporte do ingrediente ativo do defensivo agrícola através das gotas pulverizadas, devendo essas serem depositadas preferencialmente no alvo.

A definição de tecnologia de aplicação é descrita por Antuniassi et al. (2017) como o conjunto de conhecimentos que integram informações sobre produtos fitossanitários, formulações, adjuvantes, pulverizações, alvos, recursos humanos, tecnologia de informação e ambiente, visando uma aplicação correta, segura e responsável, sempre respeitando as boas práticas agrícolas.

Cunha \& Ruas (2006), citam que em grande parte dos casos os defensivos agrícolas são tidos como o foco principal das operações de pulverização, negligenciando a tecnologia de aplicação do mesmo. Segundo Antuniassi (2012), o conhecimento da melhor forma de aplicação é de extrema importância para que seja realizada de forma segura e eficiente, devendo ser ajustados os fatores de condições meteorológicas, velocidade do vento, temperatura e teor de umidade; volume de calda e tamanho de gotas por seleção de pontas de pulverização.

Segundo Balan et al. (2006), a pulverização ainda fica dependente da influência de fatores biológicos; fatores relacionados ao alvo, como a forma, tamanho e posição; e fatores relacionados às gotas, como a densidade, diâmetro e velocidade de deposição. Devendo sempre ser levado em consideração às recomendações agronômicas de cada produto (ANTUNIASSI \& BAIO, 2008).

Chechetto et al. (2013), descrevem que as pontas de pulverização, instrumentos responsáveis pela formação das gotas e seus tamanhos, são essenciais para a qualidade do processo de aplicação, tendo em vista que existe uma variação do tipo de alvo e das condições 
climáticas. Reichard et al. (1977), salientam que tais gotas devem ser grandes o suficiente para atingirem o alvo, mesmo que sofram evaporação no trajeto da ponta de pulverização até a superfície do alvo, e pequenas o suficiente para que cubram a área necessária no alvo, de modo que, o princípio ativo do defensivo seja absorvido e aja de forma adequada.

Antuniassi (2012), levanta a questão do dossel das culturas, que dificulta a penetração das gotas no terço inferior das plantas, sendo necessária a escolha de pontas que produzam gotas menores, capazes de adentrar e atingir os alvos localizados em seu interior.

Diversos agentes nocivos se desenvolvem nas partes inferiores das folhas, sendo alvos difíceis de serem atingidos em pulverizações convencionais, sem assistência de ar na barra, com isso, estudos foram realizados, a fim de, detalhar os benefícios da assistência de ar junto à barra de pulverização, tais como, melhora na deposição de produtos nas partes inferiores das plantas, redução da deriva e colocação de produtos químicos na superfície abaxial das folhas (BAUER E RAETANO, 2000). Para culturas de baixo porte, Sartori (1997) apresenta o emprego de pulverizadores com assistência de ar na barra como uma excelente ferramenta para melhorar a qualidade de aplicação, aumentar a produtividade e reduzir a deriva, visto que, a velocidade do vento da máquina é maior que a do vento ambiente.

Outro fator importante que pode influenciar na qualidade da aplicação é a interação do produto com a planta, podendo ocorrer pela parte aérea, folhas, ou pelas raízes. O desafio é maior quando a aplicação é realizada para que as gotas atinjam as folhas, visto que, existem mecanismos anatômicos da planta, tais como, cutícula foliar, que funciona como um impermeabilizante, evitando a absorção de ingredientes ativos (RODRIGUES, 2009).

Santos (2007), relata que devido a diversidade de fatores que influenciam a aplicação de defensivos agrícolas, incluindo à variação no tamanho de gotas que há em uma pulverização e o tipo de calda pulverizada, se mostra necessário avaliar o espectro de gotas das caldas através de critérios técnicos. 


\subsection{Adjuvantes}

Juntamente com as pontas, os adjuvantes constituem importante ferramenta da tecnologia de aplicação (GODINHO JUNIOR et al., (2015). A adição de adjuvantes às caldas de pulverização é uma das formas utilizadas para otimizar as aplicações de agroquímicos (VILELA, 2012).

De acordo com a legislação brasileira, Artigo $1^{\circ}$ do Decreto $n^{\circ} 4.074$, de 4 de janeiro de 2002, que regulamenta os agrotóxicos, caracteriza-se como adjuvante o "produto utilizado em mistura com produtos formulados para melhorar a sua aplicação”. Para Kissmann (1998), ele é caracterizado como "qualquer substância ou composto, sem propriedades fitossanitárias, com exceção da água, que pode ser adicionado a calda de modo a facilitar a aplicação, aumentando sua eficiência ou diminuindo riscos". Segundo Godinho Junior et al. (2015), são produtos químicos que promovem alterações na calda, atenuando os efeitos adversos ambientais e morfofisiológicos da planta, elevando a eficácia do controle.

Os adjuvantes podem ser classificados pela sua função ou composição química, no entanto, essas classificações são bastante limitadas, pois muitos produtos têm multifunções, ou composição química complexa que não é divulgada de forma integral pelos seus fabricantes. Além disso, existe uma variedade de termos utilizados pelos fabricantes, que acabam gerando confusão por parte dos usuários e especialistas (GREEN, 2000).

Essas substâncias podem exercer diversas funções na aplicação de defensivos agrícolas, tais como, quelatizantes e acidificantes, redutores de $\mathrm{pH}$ da calda, surfactantes, ativadores nitrogenados, espalhantes adesivos, antiespumantes, espessantes, entre outras (MOTA, 2011).

Segundo Vilela (2012), existe dois tipos de adjuvantes, os ativadores e os úteis. O primeiro grupo consiste em produtos capazes de influenciar na eficácia dos agroquímicos, justamente, por provocar um aumento na taxa de absorção pelos alvos. Estes estão inseridos no grupo de adjuvantes com propriedades molhantes, espalhantes, adesivos e umectantes. Pra Tu \& Randall (2001), este grupo de adjuvantes são os surfatantes, óleos vegetais, óleos comparados a metilados, óleos minerais, oriundos de silicone e fertilizantes nitrogenados.

De acordo com Hazen (2000), os adjuvantes com características molhantes são definidos pelo auxílio que promovem nas caldas, ou suspensões, para obtenção de gotas com maior ângulo de contato com o alvo, sendo, normalmente, surfatantes não iônicos. Segundo Kissmann (1998), estas substâncias apresentam sítios polares e apolares, funcionando como pontes entre 
a água, que é polar, e as superfícies apolares, configurando assim maior habilidade de molhar alvos com características hidrofóbicas. Durigan \& Correia (2008) afirmam que são substâncias que aumentam a área de cobertura do volume de um líquido sobre um sólido ou até um outro líquido, por romper a tensão superficial da água nas gotas pulverizadas. Vilela (2012) concluem que adjuvantes com características espalhantes são agentes molhantes que fazem a gota se espalhar sobre o alvo além de seu tamanho original de contato.

Há também os adjuvantes com propriedades adesivas, que segundo Hazen (2000), são empregados para auxiliar na deposição do produto aplicado com gotas de reduzido volume. Estes são adjuvantes não evaporantes, com alta resistência ao escoamento, permitindo a adesão e a efetividade do produto por um período prolongado sobre o alvo. Durigan \& Correia (2008) e Vilela (2012), definem que essas substâncias se misturam bem a água e tem forte adesão às moléculas da cutícula das folhas.

O segundo grupo de adjuvantes, útil, é capaz de agir sobre as propriedades da calda de pulverização, não afetando diretamente a eficácia do agrotóxico, porém podem reduzir os efeitos negativos da aplicação, agindo positivamente no desempenho do produto aplicado (Vilela, 2012). Hazen (2000), cita que estes adjuvantes são utilizados como compatibilizantes, antiespumantes, redutores de deriva, depositantes, condicionadores de água, acidificantes e tamponantes. Dentre as características citadas pelos autores, a de redução de deriva é a que tem maior número de pesquisas por conta da sua importância nas pulverizações agrícolas, tanto quanto pela redução da dispersão do ingrediente ativo no ambiente.

A característica de antiespumante, de acordo com a ASTM (1995), é a de eliminar ou suprimir a espuma do tanque de pulverização. Segundo Vilela (2012), antiespumantes, normalmente, são à base de silicones. $\mathrm{O}$ autor define os compatibilizantes como materiais tensoativos que permitem a aplicação simultânea de dois ou mais agentes, como defensivos agrícolas e fertilizantes, misturados no tanque de pulverização.

Godinho Junior et al. (2015), descrevem que, de uma forma geral, os adjuvantes tornam a calda menos susceptível às variações meteorológicas de umidade relativa do ar, temperatura e velocidade do vento. Montório et al. (2005), relatam que os adjuvantes podem agir diminuindo a tensão superficial das gotas pulverizadas, contribuindo para a formação de filmes líquidos sobre a superfície foliar, aumentando assim a superfície de contato e consequentemente a absorção do ingrediente ativo do defensivo. 
De acordo com Gent et al. (2003), alguns adjuvantes são capazes de provocar retenção das gotas nas superfícies vegetais, considerados aspectos positivos principalmente em aplicações com taxas reduzidas.

Antuniassi \& Baio (2008), chamam atenção para os problemas relacionados ao uso indevido dos adjuvantes pelo desconhecimento de sua ação, podendo até interferir na ação do produto principal, ou então, mudar suas características de forma significativa, tornando o uso desnecessário. Ainda de acordo com os autores, dependendo das características da calda, ao adicionar adjuvante o processo de formação das gotas pelas pontas de pulverização pode ser alterado.

Adjuvantes adicionados a calda podem modificar as características da calda de aplicação (MOREIRA JUNIOR \& ANTUNIASSI, 2010). Algumas misturas de tanque com adjuvante podem influenciar a compatibilidade entre produtos, solubilidade, estabilidade, proteção e formação de espuma, o processo de aplicação (deriva e evaporação), a retenção (rebote e adesão), a deposição (molhamento, espalhamento, sublimação) e a translocação na planta (GREEN, 2000).

Felsot et al. (2010), mencionam que os adjuvantes podem influenciar fatores que são determinantes para a deriva, como o tamanho das gotas pulverizadas. Em condições de campo, Johnson et al. (2006), obtiveram redução de deriva com adjuvante voltado para esse fim. Utilizando adjuvante do tipo óleo vegetal na concentração de $1 \%$ da calda, Costa et al. (2008) verificaram aumento no tamanho das gotas e redução de deriva durante a aplicação de herbicida 2,4-D + Glyfhosate em condições controladas.

Apesar dos adjuvantes serem considerados entre tecnologias que podem influenciar a deriva de herbicidas, Costa et al. (2014) descrevem que ainda são escassos os estudos disponíveis a esse respeito no Brasil, principalmente em condições de campo. 


\section{MATERIAL E MÉTODOS}

\subsection{Campo experimental}

O ensaio foi realizado a campo na Fazenda Experimental Água Limpa (FAL), situada em Brasília-DF e pertencente à Universidade de Brasília (UnB).

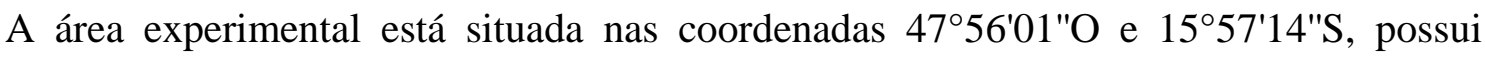
altitude média de $1100 \mathrm{~m}$, clima subtropical de inverno seco, com temperaturas inferiores a $18^{\circ} \mathrm{C}$, e verão quente, com temperaturas superiores a $22^{\circ} \mathrm{C}$.

Para a realização do experimento a área foi cultivada com a cultivar de soja AS3680, cujas características agronômicas são de ciclo médio de 104 dias, hábito de crescimento indeterminado, arquitetura de planta ereta e bom engalhamento.

\subsection{Delineamento experimental e descrição dos tratamentos}

Os fatores estudados neste trabalho foram a utilização de adjuvante na calda (adjuvante) e assistência de ar na barra do pulverizador (assistência de ar).

O delineamento experimental utilizado foi o inteiramente casualizado, sendo os tratamentos constituído por um fatorial 2 × 2 (calda: com e sem adjuvante; aplicação: com e sem assistência de ar na barra de pulverização) com seis repetições cada, totalizando 24 parcelas experimentais.

Os tratamentos foram identificados por: calda sem adjuvante e com assistência de ar na barra de pulverização (T1), calda sem adjuvante e sem assistência de ar na barra de pulverização (T2), calda com adjuvante e com assistência de ar na barra de pulverização (T3), calda com adjuvante e sem assistência de ar na barra do pulverizador (T4).

As parcelas experimentais foram dimensionadas com três metros de comprimento e $14 \mathrm{~m}$ de largura, totalizando $42 \mathrm{~m}^{2}$ cada. As parcelas experimentais foram distribuídas em campo conforme ilustra o croqui da Figura 1. 


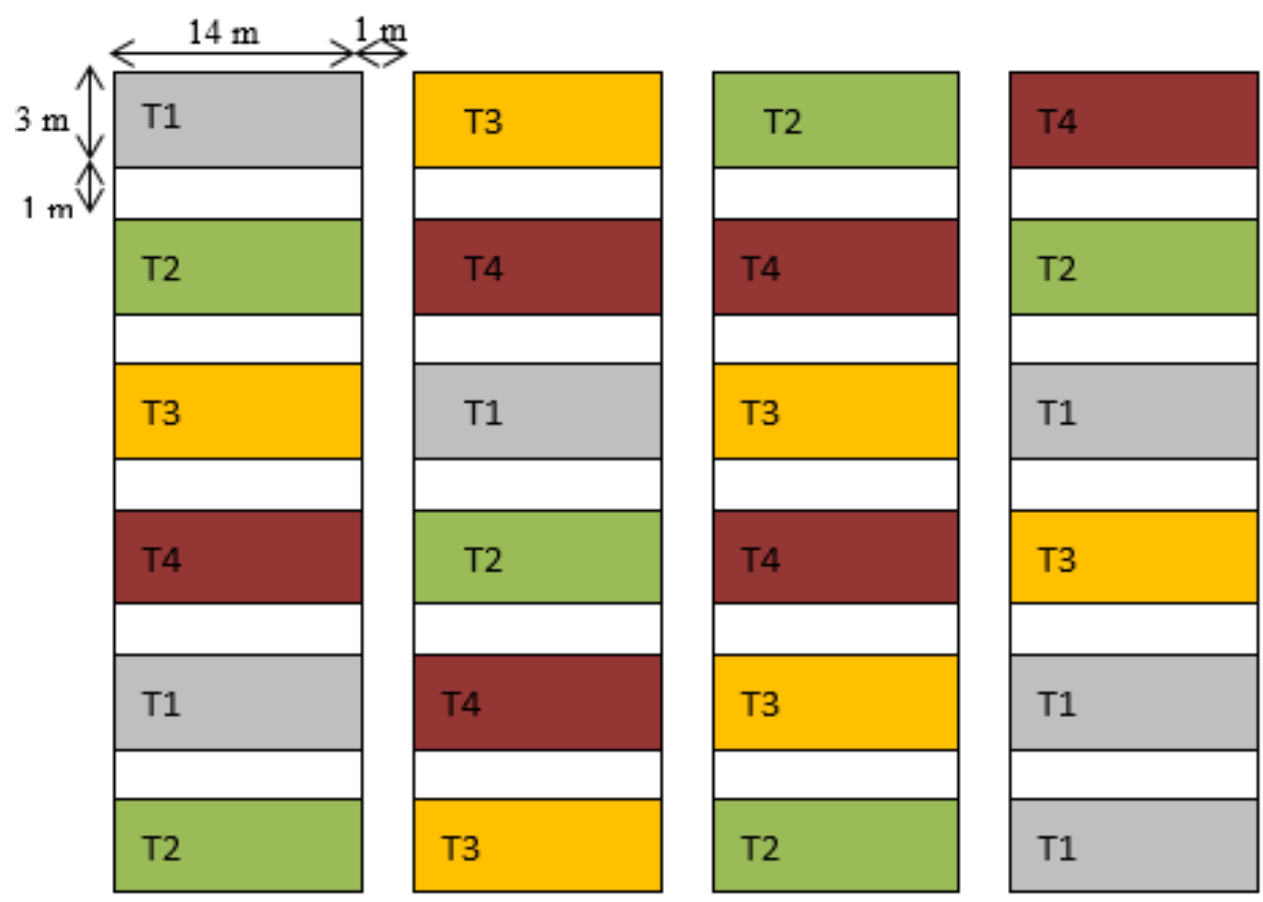

Figura 1. Croqui da área experimental, com a distribuição das parcelas.

\subsection{Condições meteorológicas}

As condições meteorológicas médias de temperatura (T), umidade relativa do ar (UR) e velocidade do vento (V) durante a realização do ensaio são apresentadas na Figura 2, e foram obtidas utilizando um anemômetro digital marca Akso modelo AK835, e um termo-higrômetro marca Akso, modelo AK28.

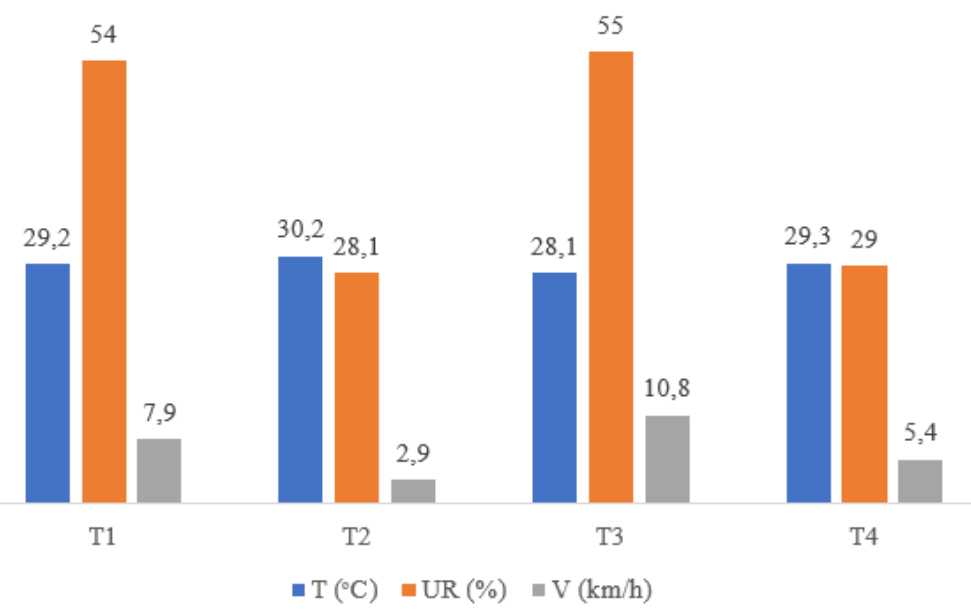

Figura 2. Condições meteorológicas durante a realização do ensaio. 


\subsection{Adjuvante e formulação da calda de pulverização}

O adjuvante utilizado foi do fabricante Agecom, nome comercial Agefix. Conforme informações da bula o produto é um concentrado emulsionável composto por hidrocarbonetos parafínicos, ciclo parafínicos e aromáticos saturados e insaturados provenientes da destilação do petróleo, com $920 \mathrm{~g} / \mathrm{L}$ de óleo mineral e $80 \mathrm{~g} / \mathrm{L}$ de ingredientes inertes.

O Agefix é recomendado pelo fabricante para melhor distribuição, redução da tensão superficial e aderência das caldas na superfície da planta, apresentando efeito molhante e espalhante, já que as gotículas de água emulsionadas com óleo mineral evaporam mais lentamente, permitindo alcançar o alvo e facilitar a absorção de produtos hidrossolúveis.

A calda de pulverização foi formulada com água + adjuvante, sendo a dosagem utilizada do adjuvante referente à concentração de $1 \%$ do volume de calda, conforme recomendação da bula do produto.

\subsection{Máquinas e implementos}

O pulverizador utilizado foi o tratorizado da marca Jacto, modelo Falcon Vortex AM14, de acoplamento montado, tanque com capacidade de $600 \mathrm{~L}$, sendo a agitação da calda realizada via força hidráulica. Possui o sistema Vortex de assistência de ar na barra, $14 \mathrm{~m}$ de barras, manômetro analógico de até $16 \mathrm{kgf} \mathrm{cm}^{-2}$ e 29 bicos espaçados a $0,5 \mathrm{~m}$. A velocidade do ar utilizada no sistema Vortex foi de $4,2 \mathrm{~m} \mathrm{~s}^{-1}$, medida com anemômetro digital informado no item 4.3 .

O pulverizador foi acoplado a um trator da marca New Holland, modelo TL85E 4 x 2 TDA, de $61 \mathrm{~kW}(83 \mathrm{cv})$ de potência no motor. O conjunto mecanizado utilizado é ilustrado nas Figuras 3 e 4. 


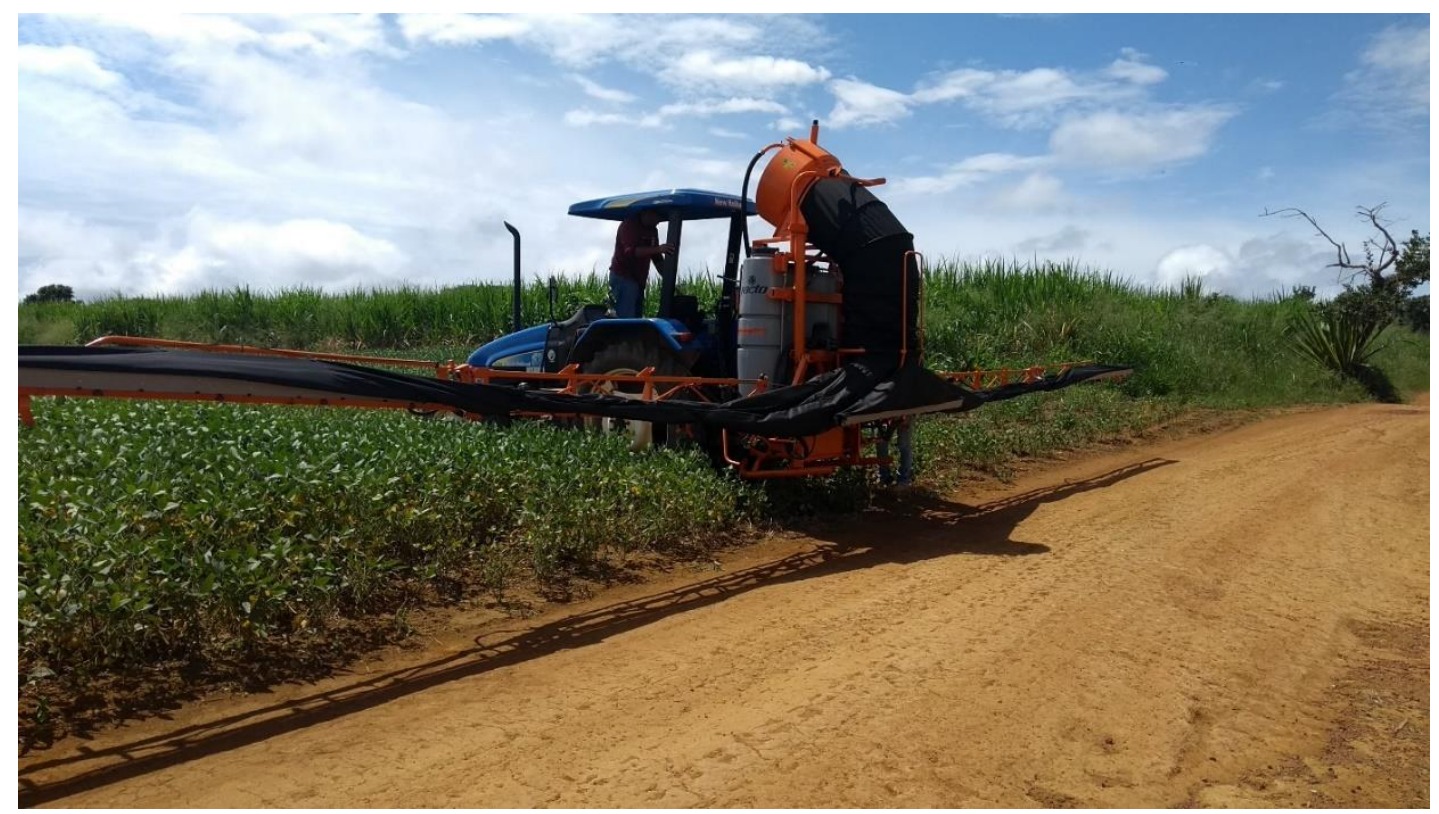

Figura 3. Conjunto mecanizado sem assistência de ar na barra do pulverizador.

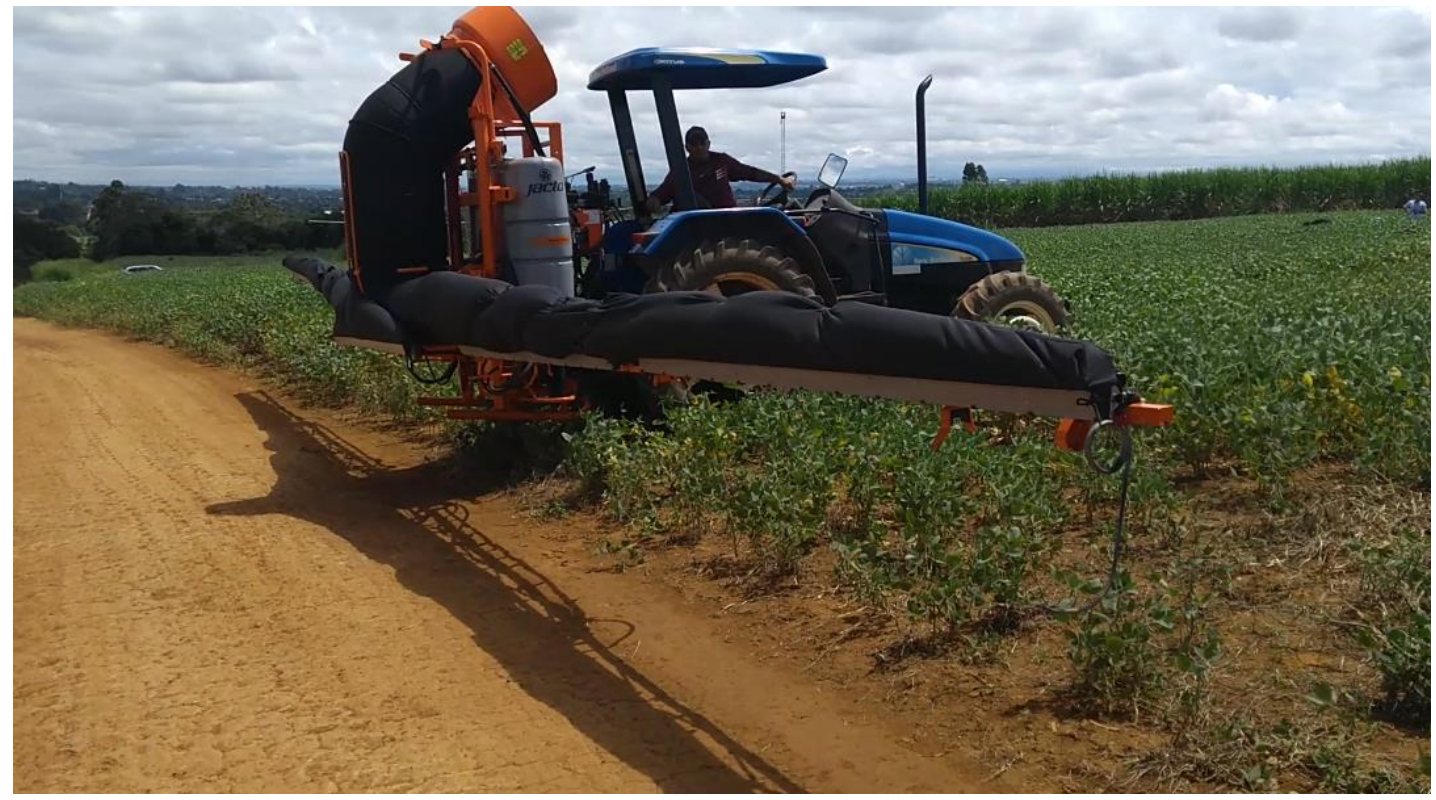

Figura 4. Conjunto mecanizado com assistência de ar na barra do pulverizador.

As pontas de pulverização utilizadas nos bicos foram da marca Jacto, ADI110015, com filtro de malha 100, do tipo leque, faixa de pressão recomendada de 30 a 75 psi, vazão de 0,49 a $0,77 \mathrm{~L} \mathrm{~min}^{-1}$ e diâmetro mediano volumétrico (DMV) de gotas médias.

De acordo com a norma S572.1 (ASABE, 2018), de classificação de pontas de pulverização por espectro de gotas, gotas médias são aquelas cujo tamanho do DMV está entre 236 a $350 \mu \mathrm{m}$. 


\subsection{Aplicação dos tratamentos e coleta das gotas pulverizadas}

As aplicações dos tratamentos foram realizadas em 11 de março de 2019 entre 11:25 e 15:00 horas.

A cultura da soja encontrava-se em estágio de desenvolvimento R7, com plantas de altura média $0,75 \mathrm{~m}$.

A velocidade operacional utilizada durante a coleta dos dados foi de $6 \mathrm{Km} \mathrm{h}^{-1}$, com rotação nominal de $540 \mathrm{rpm}$ na tomada de potência, sendo calibrada a pressão de 55 psi para taxas de aplicações de $0,75 \mathrm{~L} \mathrm{~min}^{-1}$ (equivalente a $150 \mathrm{~L} \mathrm{ha}^{-1}$ ).

Para a coleta das gotas pulverizadas foi utilizada a metodologia descrita por Baio et al. (2015). Papeis fotográficos de dimensões 76 x $26 \mathrm{~mm}$ foram fixados com grampos sobre o limbo superior das folhas de soja, no terço inferior das plantas, atentando para que a face fotográfica (lisa) do papel estivesse voltada para cima. Para que o papel fotográfico fosse colorido pelas gotas aplicadas foi utilizado o corante preto da marca Xadrez ${ }^{\circledR}$ na concentração de 2,5\% do volume de calda de pulverização.

Foram utilizados seis papeis por parcela, sendo um por planta escolhida aleatoriamente. Após a aplicação os papeis foram coletados, identificados e armazenados em embalagem de papel, para posterior avaliação.

\subsection{Avaliações do espectro de gotas}

Os papéis fotográficos amostrados (Figura 5) foram digitalizados em escâner de mesa marca Epson modelo L355 ecotank com resolução de 1200 dpi.

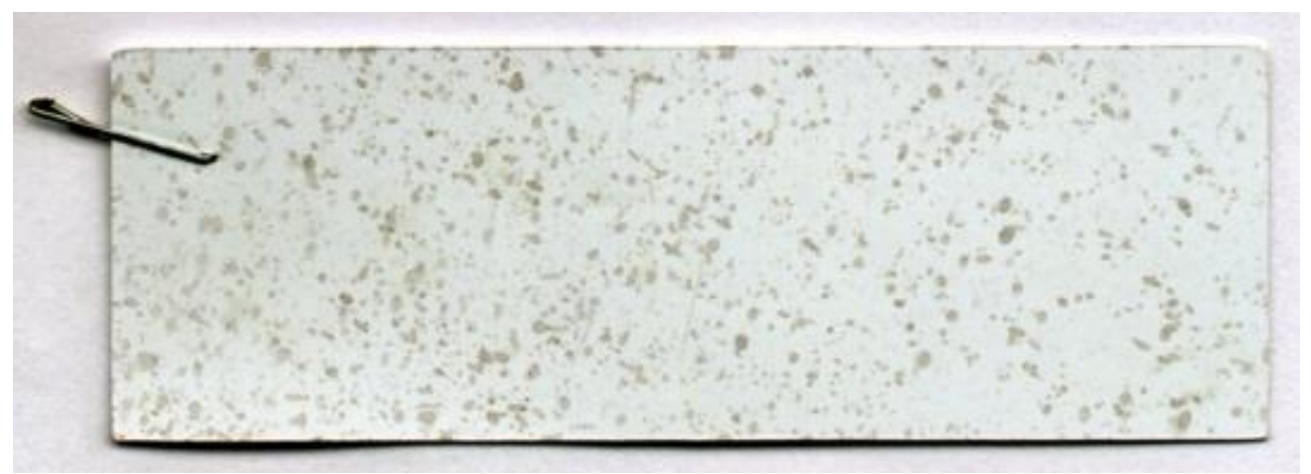

Figura 5. Amostra de papel fotográfico marcado com corante preto. 
As imagens foram analisadas pelo programa computacional Gotas (EMBRAPA, 2015), sendo obtidos dados de diâmetro mediano volumétrico das gotas (DMV), diâmetro de gotas, tal que, $10 \%$ do volume do líquido pulverizado é constituído de gotas de tamanho menor que esse valor $\left(\mathrm{DV}_{0,1}\right)$, diâmetro de gota tal que $90 \%$ do volume do líquido pulverizado é constituído de gotas de tamanho menor que esse valor $\left(\mathrm{DV}_{0,9}\right)$, porcentagem de gotas menores que $100 \mu \mathrm{m}$ $(\% \leq 100 \mu \mathrm{m})$, e a amplitude relativa (AR) das gotas.

A variável AR das gotas foi determinada pela Equação 1.

$$
\mathrm{AR}=\frac{D V_{0,9}-D V_{0,1}}{D M V}
$$

AR - amplitude relativa das gotas;

DV 0,9 - diâmetro de gota tal que $90 \%$ do volume do líquido pulverizado é constituído de gotas de tamanho menor que esse valor $(\mu \mathrm{m})$;

$\mathrm{DV}_{0,1}$ - diâmetro de gota tal que $10 \%$ do volume do líquido pulverizado é constituído de gotas de tamanho menor que esse valor $(\mu \mathrm{m})$;

DMV - diâmetro mediano volumétrico das gotas $(\mu \mathrm{m})$.

\subsection{Análise estatística}

Os dados obtidos foram submetidos à análise de variância (ANOVA) e as médias comparadas pelo teste de Tukey ao nível de 5\% de probabilidade de erro. 


\section{RESULTADOS E DISCUSSÃO}

Os resultados da análise de variância (ANOVA) para efeitos principais e interações entre os fatores aplicação e calda, para as variáveis porcentagem do volume de gotas com diâmetro menor ou igual a $100 \mu \mathrm{m}(\% \leq 100 \mu \mathrm{m})$, diâmetro mediano volumétrico (DMV), amplitude relativa (AR), cobertura do alvo e volume aplicado, são apresentados na Tabela 1.

Tabela 1. Interação entre o fator calda e aplicação para a variável porcentagem do volume de gotas com diâmetro menor ou igual a $100 \mu \mathrm{m}(\% \leq 100 \mu \mathrm{m})$.

\begin{tabular}{|c|c|c|c|c|c|}
\hline \multicolumn{6}{|c|}{ ANOVA } \\
\hline Fator & Teste F & P valor & DP & EP & $\mathbf{C V}$ \\
\hline \multicolumn{6}{|c|}{ Variável: $\% \leq 100 \mu \mathrm{m}$} \\
\hline Aplicação (A) & $223,69 * *$ & $<0,0001$ & & & \\
\hline Calda (B) & $16,51 * *$ & 0,0006 & 0,575 & 0,234 & 5,15 \\
\hline$A \times B$ & $0,60^{\mathrm{NS}}$ & 0,446 & & & \\
\hline \multicolumn{6}{|c|}{ Variável: DMV $(\mu \mathrm{m})$} \\
\hline Aplicação (A) & $1,47^{\mathrm{NS}}$ & 0,238 & & & \\
\hline Calda (B) & $1772,28 * *$ & $<0,0001$ & 1,640 & 0,669 & 0,50 \\
\hline $\mathrm{A} \times \mathrm{B}$ & $1,47^{\mathrm{NS}}$ & 0,238 & & & \\
\hline \multicolumn{6}{|c|}{ Variável: AR } \\
\hline Aplicação (A) & $559,26 * *$ & $<0,0001$ & & & \\
\hline Calda (B) & $519,93 * *$ & $<0,0001$ & 0,006 & 0,002 & 0,82 \\
\hline $\mathrm{A} \times \mathrm{B}$ & $4,80 *$ & 0,040 & & & \\
\hline \multicolumn{6}{|c|}{ Variável: Cobertura do alvo (\%) } \\
\hline Aplicação (A) & $748,98 * *$ & $<0,0001$ & & & \\
\hline Calda (B) & $1301,55^{* *}$ & $<0,0001$ & 1,094 & 0,446 & 4,61 \\
\hline $\mathrm{A} \times \mathrm{B}$ & $11,44 * *$ & $<0,0001$ & & & \\
\hline \multicolumn{6}{|c|}{ Variável: Volume aplicado $\left(\mathrm{L} \mathrm{ha}^{-1}\right)$} \\
\hline Aplicação (A) & $1428,02 * *$ & 0,0001 & & & \\
\hline Calda (B) & $52,50 * *$ & 0,0001 & 2,681 & 1,094 & 4,50 \\
\hline $\mathrm{A} \times \mathrm{B}$ & $8,77 * *$ & 0,0077 & & & \\
\hline
\end{tabular}

*Significativo ao nível de 5\% de probabilidade de erro. **significativo ao nível de $1 \%$ de probabilidade de erro. DP: desvio padrão residual; EP: erro padrão da média; CV: coeficiente de variação. O grau de liberdade foi igual a um pra todos os fatores e interações, em todas as variáveis.

De acordo com a ANOVA não foi verificada interação significativa entre os fatores para as variáveis $\% \leq 100 \mu \mathrm{m}$ e DMV, sendo que os resultados de DMV somente diferiram quando comparadas as médias em função do fator calda. Para as demais variáveis os fatores apresentaram interação significativa. 
Os resultados de comparação de médias de $\% \leq 100 \mu \mathrm{m}$ e DMV são apresentados na Figura 6 e 7 respectivamente.

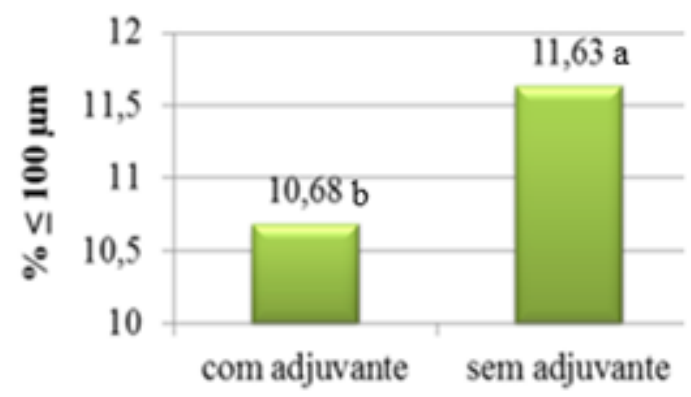

Figura 6. Porcentagem do volume de gotas com diâmetro menor que $100 \mu \mathrm{m}(\% \leq 100 \mu \mathrm{m})$ com e sem adjuvante na calda.

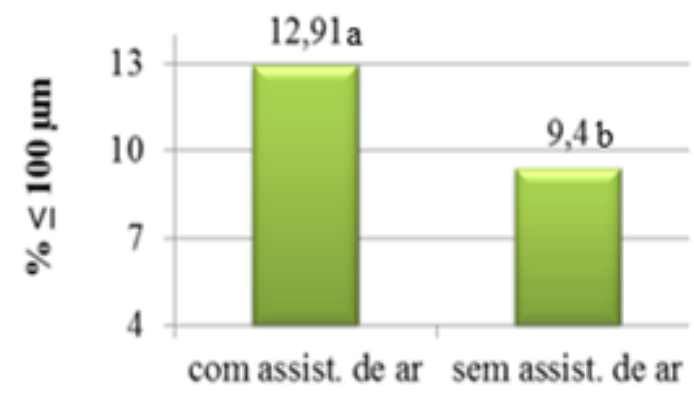

Figura 7. Porcentagem do volume de gotas com diâmetro menor que $100 \mu \mathrm{m}(\% \leq 100$ $\mu \mathrm{m})$ na aplicação com e sem assistência de ar na barra do pulverizador.

Verificou-se que no fator calda (Figura 6), os resultados de $\% \leq 100 \mu \mathrm{m}$ diferiram entre utilizar e não utilizar adjuvante. Com adjuvante na calda foi verificado $10,68 \%$ de gotas com diâmetro $\leq 100 \mu \mathrm{m}$, resultado $0,95 \%$ menor que o obtido sem adjuvante na calda.

Possivelmente o menor valor obtido de $\% \leq 100 \mu \mathrm{m}$ ocorre devido o que descreve Cunha \& Peres (2010), que adjuvante do tipo óleo mineral proporciona gotas que reduzem a tensão superficial, elevam o efeito molhante e espalhante da mesma sobre o alvo, já que as gotas emulsionadas com óleo evaporam mais lentamente. Dessa forma as gotas que atingem o alvo adquirem maior estabilidade e menor risco de deriva. Antuniassi (2006), cita que o processo de formação das gotas pode ser facilmente alterado, de acordo com produtos e formulações adotadas, com a adição de químicos e adjuvantes, estes alteram as características químicas e 
físicas da calda, como a viscosidade e tensão superficial, fatores que possivelmente contribuíram para menor $\% \leq 100 \mu \mathrm{m}$ obtido no trabalho.

Os resultados corroboram com os encontrados por Cunha \& Alves (2009), que em estudo sobre adjuvantes na calda de aplicação verificaram $17,83 \%$ de gotas $\leq 100 \mu \mathrm{m}$, valor $3,22 \%$ maior que o encontrado quando na aplicação somente com água. Os autores comprovam e descrevem a eficiência dos adjuvantes para a produção de gotas de maior diâmetro e citam serem gotas mais seguras ao risco de perdas por deriva.

Para o fator aplicação (Figura 7), foi verificada diferença de \% de gotas $\leq 100 \mu \mathrm{m}$ na aplicação com e sem assistência de ar na barra do pulverizador. Com assistência de ar na barra foi obtido $12,91 \%$ de gotas com diâmetro $\leq 100 \mu \mathrm{m}$, valor 3,5\% maior que o obtido na aplicação sem assistência de ar na barra do pulverizador. O resultado pode ser compreendido possivelmente pela maior velocidade de deslocamento da gota até o alvo, possibilitando que maior quantidade de gotas atinjam a superfície do alvo, mesmo que no terço inferior da planta, local de mais difícil acesso. O resultado torna possível descrever que com assistência de ar na barra é maior a assertividade de gotas muito finas sobre o alvo, sendo intuitiva a possibilidade de menor risco de perdas por exoderiva.

A justificativa pode ser compreendida em função do que explica Raetano (2002) sobre a pulverização de gotas com pulverizadores convencionais, sem assistência de ar na barra. De acordo com o autor após a saída do líquido pressurizado pelos bicos de pulverização, se perde de 50 a 70\% de sua energia, a energia residual se manifesta em forma de movimento. A redução desse momento se dá principalmente pela resistência do ar, portanto, gotas ao ar com menor momento são mais suscetíveis à deriva. Esse fator pode ser superado por gotas lançadas em fluxo direcional de ar com maior velocidade, efeito produzido por barras de pulverização com assistência ar. Nessa condição a velocidade de deslocamento das gotas soma a velocidade de deslocamento do ar emitido pela barra, acelerando o tempo necessário para seu trajeto até o alvo, reduzindo o risco de deriva.

Bauer \& Raetano (2000), avaliaram o efeito da assistência de ar na barra do pulverizador para a deposição de gotas e perdas de produtos fitossanitários na cultura da soja, e constataram no alvo maior número de gotas aerotransportadas. Os autores constataram ainda menor deriva por sedimentação em áreas adjacentes a cultura. Koch (1997), afirma que a assistência de ar pressurizado na barra leva a melhores níveis de penetração de gotas da pulverização no interior da cultura, especialmente em culturas onde a densidade foliar é alta. 
Os resultados de DMV apresentados na Figura 8 indicam aumento do tamanho de gotas utilizando adjuvante na calda de pulverização. Com adjuvante o DMV das gotas foi de 341,24 $\mu \mathrm{m}$, sendo $8,26 \%$ maior que o obtido sem adjuvante. Os resultados podem ser compreendidos em função do que descreve Vargas \& Roman (2006), que os adjuvantes atuam como espalhante, desta forma, as gotas contendo esses produtos tendem a abranger maior superfície de contato sobre o alvo, indicando assim maior DMV das gotas e cobertura do alvo. Segundo Oliveira (2011), os adjuvantes são produtos que aumentam a viscosidade da calda, consequentemente, aumentando o DMV das gotas aplicadas.

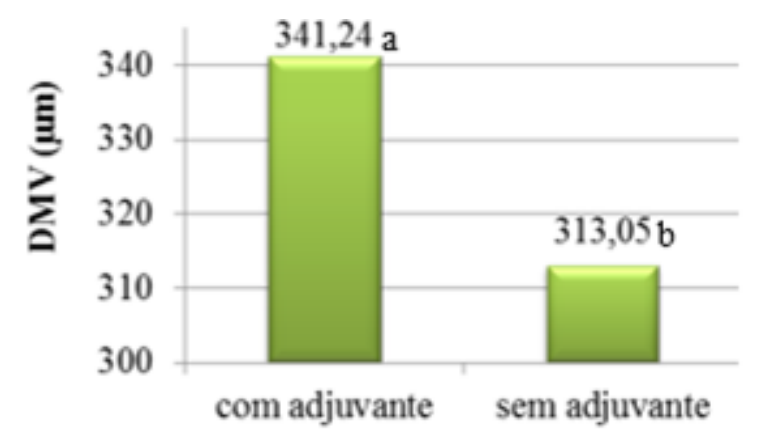

Figura 8. Diâmetro mediano volumétrico das gotas (DMV) com e sem adjuvante na calda.

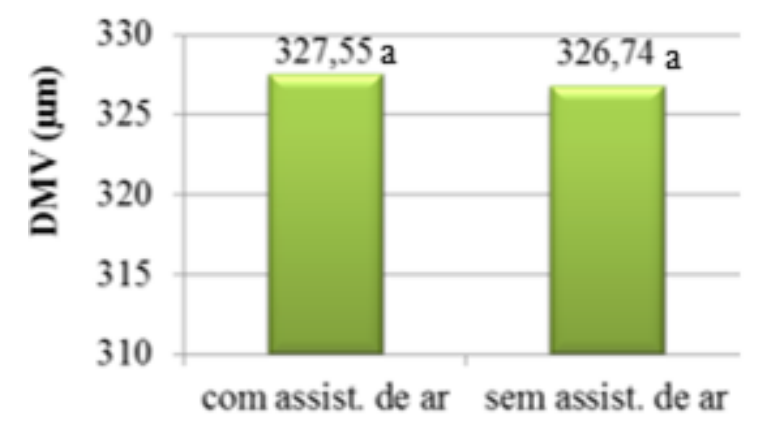

Figura 9. Diâmetro mediano volumétrico das gotas (DMV) na aplicação com e sem assistência de ar na barra de pulverização.

Em se tratando dos resultados de DMV da Figura 9, não foram verificadas diferenças para aplicação com e sem assistência de ar na barra de pulverização. O DMV médio obtido foi de $327,14 \mu \mathrm{m}$. O resultado demonstra que a assistência de ar na barra não influencia o espectro de gotas, pois segundo Koch (1997) e Scudeler (2005) a tecnologia de barra assistida por ar é definida como uma cortina de ar em alta velocidade sendo incidida sobre o jato de pulverização. 
Tal cortina de ar, tem por finalidade aumentar a velocidade vertical das gotas e não alterar o espectro de gotas geradas pelas pontas.

Os resultados de interação entre os fatores para a variável amplitude relativa da população de gotas (AR) são apresentados na Tabela 2.

Tabela 2. Interação entre o fator calda e aplicação para os resultados de amplitude relativa (AR), do tamanho das gotas.

\begin{tabular}{lcc}
\hline \multirow{2}{*}{ Aplicação } & \multicolumn{2}{c}{ AR } \\
\cline { 2 - 3 } & \multicolumn{2}{c}{ Calda } \\
\cline { 2 - 3 } & Sem adjuvante & Com adjuvante \\
\hline Sem assist. de ar na barra & $0,88 \mathrm{aA}$ & $0,82 \mathrm{aB}$ \\
Com assist. de ar na barra & $0,83 \mathrm{bA}$ & $0,76 \mathrm{bB}$ \\
\hline Média & \multicolumn{2}{c}{0,82} \\
\hline DMS (5\%) & \multicolumn{2}{c}{0,008} \\
\hline CV (\%) & \multicolumn{2}{c}{0,82} \\
\hline $\begin{array}{l}\text { Médias seguidas pela mesma letra minúscula na coluna e maiúscula na linha não diferem } \\
\text { pelo teste de Tukey ao nível de 5\% de probabilidade de erro. DMS: diferença mínima } \\
\text { significativa; CV: coeficiente de variação. }\end{array}$
\end{tabular}

Comparando as formas de aplicação a AR foi menor para a realizada com assistência de ar na barra, independente da utilização de adjuvante, sendo de 0,83 utilizando a calda sem adjuvante e 0,76 utilizando calda com adjuvante. Em relação a AR obtida na aplicação sem assistência de ar na barra, esses valores foram respectivamente 5,68 e 7,31\% maiores.

Para a análise comparativa entre os tipos de calda a AR foi menor utilizando adjuvante, seja na aplicação sem ou com assistência de ar na barra. Na aplicação sem assistência de ar a calda com adjuvante proporcionou AR de 0,82 , sendo 6,81\% menor que a obtida sem adjuvante na mesma aplicação. Na aplicação com assistência de ar a AR foi de 0,76 para calda com adjuvante, valor 8,43\% menor que o obtido sem adjuvante na mesma aplicação.

Conforme explica Viana et al. (2010), quanto maior o valor da AR, maior é a faixa de tamanho das gotas pulverizadas e, espectro de gotas homogêneo tem valor de amplitude relativa que tende a zero. Sendo assim, é possível destacar que a AR da interação entre aplicação com assistência de ar na barra e adjuvante na calda possibilita condição de aplicação com espectro de gotas mais uniforme e, esse resultado analisado conjuntamente com o resultado de DMV da Figura 8, indica população de gotas com tamanho característico de 341,24 $\mu \mathrm{m}$. De acordo com a norma S572 (ASAE, 1999) que classifica gotas em categoria por tamanho do DMV, 341,24 $\mu \mathrm{m}$ são classificadas em gotas médias. 
Os resultados de interação para a variável cobertura do alvo por gotas de pulverização são apresentados na Tabela 3.

Tabela 3. Interação dos fatores calda e aplicação para a variável cobertura do alvo.

\begin{tabular}{|c|c|c|}
\hline \multirow{3}{*}{ Aplicação } & \multicolumn{2}{|c|}{ Cobertura do alvo (\%) } \\
\hline & \multicolumn{2}{|c|}{ Calda } \\
\hline & Sem adjuvante & Com adjuvante \\
\hline Sem assist. de ar na barra & $11,88 \mathrm{bB}$ & $23,28 \mathrm{bA}$ \\
\hline Com assist. de ar na barra & $19,39 \mathrm{aB}$ & $40,22 \mathrm{aA}$ \\
\hline Média & \multicolumn{2}{|c|}{23,69} \\
\hline DMS (5\%) & \multicolumn{2}{|c|}{1,317} \\
\hline $\mathrm{CV}(\%)$ & \multicolumn{2}{|c|}{4,61} \\
\hline
\end{tabular}

O fator aplicação diferiu a porcentagem de cobertura do alvo para calda sem e com adjuvante. Com assistência de ar na barra e sem adjuvante na calda foi obtido 19,39\% de cobertura do alvo, valor 38,7\% maior que o obtido sem assistência de ar em mesma calda. Com adjuvante na calda a aplicação com assistência de ar proporcionou 40,22\% de cobertura do alvo, sendo $42,1 \%$ maior que a cobertura da mesma calda aplicada sem assistência de ar na barra.

O fator calda diferiu a cobertura do alvo de forma que maiores valores foram obtidos com adjuvante na calda, aplicada sem e com assistência de ar na barra. Para aplicação sem assistência de ar na barra a calda com adjuvante proporcionou $23,28 \%$ de cobertura do alvo, porcentagem 48,9\% maior que a obtida pela calda sem adjuvante. Para aplicação com assistência de ar na barra os resultados foram semelhantes, sendo $51,7 \%$ maior a cobertura do alvo utilizando calda com adjuvante.

A maior cobertura do alvo, 40,22\%, obtida pela interação entre calda com adjuvante e aplicação com assistência de ar na barra, pode ser compreendida pelo que descreve ASTM (1995). De acordo com o autor os adjuvantes adicionados a calda de pulverização reduzem de forma significativa a deriva, aumentando o percentual de deposição de gotas com produto sobre os alvos. Segundo Mcmullan (2000), adjuvantes tendem a elevar o DMV das gotas aplicadas e consequentemente é reduzido o risco de perdas para o ambiente, proporcionando maiores chances de elas atingirem o alvo e cobrirem o mesmo. Diante do discutido é compreensível que adjuvante na calda de pulverização aumenta a possibilidade de maior quantidade de gotas depositadas no alvo. 
A presença de assistência de ar na barra de pulverização possibilita maior cobertura do alvo em função de favorecer o transporte das gotas até ele. Koch (1997), Scudeler (2005) e Bauer \& Raetano (2000) explicam que a cortina de ar em alta velocidade emitida pela barra do pulverizador além de incrementar a velocidade de deslocamento ás gotas, favorece a turbulência de ar com gotas entre as folhas da cultura, mesmo nas áreas mais internas e baixeiras, possibilitando maior penetração e distribuição de gotas nas plantas, resultando maior cobertura no perfil vertical da lavoura.

Os resultados de interação para a variável volume depositado de calda sobre o alvo são apresentados na Tabela 4.

Tabela 4. Interação dos fatores calda e aplicação para a variável volume depositado de calda sobre o alvo.

\begin{tabular}{lcc}
\hline \multirow{2}{*}{ Aplicação } & \multicolumn{2}{c}{ Volume depositado (L ha $\left.\mathbf{~ h a}^{-1}\right)$} \\
\cline { 2 - 3 } & \multicolumn{2}{c}{ Calda } \\
\cline { 2 - 3 } & Sem adjuvante & Com adjuvante \\
\hline Sem assist. de ar na barra & $36,50 \mathrm{bB}$ & $41,19 \mathrm{bA}$ \\
Com assist. de ar na barra & $74,63 \mathrm{aB}$ & $85,80 \mathrm{aA}$ \\
\hline Média & \multicolumn{2}{c}{59,53} \\
\hline DMS (5\%) & \multicolumn{2}{c}{3,229} \\
\hline CV (\%) & 4,50 \\
\hline édias seguidas pela mesma letra minúscula na coluna e maiúscula na linha não diferem \\
elo teste de Tukey ao nível de 5\% de probabilidade de erro. DMS: diferença mínima \\
gnificativa; CV: coeficiente de variação.
\end{tabular}

Foram verificadas diferenças entre os fatores aplicação e calda para a variável volume depositado. Comparando as aplicações sem e com assistência de ar em cada calda individualmente, foram verificados menores volumes de deposição para aplicação sem assistência de ar. Para aplicação sem assistência de ar de calda sem adjuvante o volume depositado foi de $36,5 \mathrm{~L} \mathrm{ha}^{-1}$ no terço inferior da cultura da soja, volume $38,13 \mathrm{~L} \mathrm{ha}^{-1}$, ou $51,09 \%$, menor que o obtido na aplicação da mesma calda com assistência de ar na barra. Para aplicação com assistência de ar de calda com adjuvante o volume depositado foi $85,8 \mathrm{~L} \mathrm{ha}^{-1}$, volume 44,61 $\mathrm{L} \mathrm{ha}^{-1}$, ou 51,99\%, maior que o obtido na aplicação da mesma calda sem assistência de ar na barra. Os resultados permitem compreender que a assistência de ar na barra dobra o volume depositado de calda no terço inferior da cultura da soja.

Comparando as caldas em cada forma de aplicação individualmente foram obtidos maiores volumes depositados para calda com adjuvante. Com adjuvante o volume depositado 
foi de 41,19 $\mathrm{L} \mathrm{ha}^{-1}$ na aplicação sem assistência de ar na barra, volume 11,38\% maior que o obtido com calda sem adjuvante. Na aplicação com assistência de ar na barra a calda sem adjuvante possibilitou 74,63 $\mathrm{L} \mathrm{ha}^{-1}$ de volume depositado, quantidade $13 \%$ menor que a obtida com adjuvante na calda.

Os resultados possivelmente ocorreram em virtude dos fatores discutidos nos resultados de cobertura do alvo, embora as variáveis não sejam dependentes. Maior volume depositado de calda obtido pela interação entre calda com adjuvante e aplicação com assistência de ar na barra ocorrem pela menor vulnerabilidade das gotas à deriva, garantindo maior número de gotas no alvo, e maior velocidade de deslocamento e infiltração das mesmas no interior do volume foliar e terço inferior da cultura. 


\section{CONCLUSÕES}

Para as condições em que foram realizadas o trabalho, conclui-se que:

Com adjuvante adicionado a calda, é menor a porcentagem de gotas extremamente finas. Com assistência de ar na barra a porcentagem de deposição de gotas extremamente finas é maior.

O diâmetro mediano volumétrico das gotas é maior com adjuvante, a variável não difere para aplicação com e sem assistência de ar na barra do pulverizador.

A interação calda com adjuvante e assistência de ar na barra do pulverizador, proporciona gotas menor amplitude relativa do espectro de gotas, maior cobertura do alvo e volume depositado. 


\section{REFERÊNCIAS BIBLIOGRÁFICAS}

AMERICAN SOCIETY FOR TESTING AND MATERIALS. Designation: E1519 - 10: standard terminology relating to agricultural tank mix adjuvants. West Conshohocken, 1995.

ANTUNIASSI, U. R. Tecnologia de aplicação: Conceitos básicos, inovações e tendências. In: TOMQUELSKI, G. V. et al. (Eds.). Publicações Fundação Chapadão: Soja e Milho 2011/2012. 5 ed. Chapadão do Sul: Fundação Chapadão. 2012. cap. 16, p. 113-139.

ANTUNIASSI, U. R.; CARVALHO, F. K.; MOTA, A. A. B.; CHECHETTO, R. G. Tecnologia de Aplicação: Definição e Princípios Básicos. In: ANTUNIASSI, U. R.; CARVALHO, F. K.; MOTA, A. A. B.; CHECHETTO, R. G. Entendendo a Tecnologia de Aplicação. 1. ed. Botucatu: FEPAF, 2017. p. 9-11.

ANTUNIASSI, U. R.; BAIO, F. H. R. Tecnologia de aplicação de defensivos. In: VARGAS, L.; ROMAN, E. S. Manual de manejo e controle de plantas daninhas. Passo Fundo, Embrapa Trigo, 2008. p. 174-175.

ANTUNIASSI, U. R. Tecnologia de aplicação de defensivos. Revista Plantio Direto, v. 15, p. 17-22, 2006.

ASABE, American Society of Agricultural and Biological Engineers. 2018. ASABE S572.1

Droplet Size Classification. Disponível em: <https://cdn2.hubspot.net/hub/95784/file32015844-pdf/docs/asabe_s572.1_droplet_size_classification.pdf> Acesso em: 20/06/2019.

ASAE, 1999. Journal of Plant Protection Research, V. 52, N.4, 2012. Disponível em: file:///C:/Users/PedroNot/Downloads/JPPR_524_11_Fritz.pdf > Acesso em: 21/06/2019.

BALAN, M. G.; ABI SAAB, O. J. G.; SASAKI, E. H. Deposição da calda pulverizada por três pontas de pulverização sob diferentes condições meteorológicas. Ciência Rural, Santa Maria, v. 36, n. 3, p. 731-738, 2006.

BAUER, F.C. \& RAETANO, C.G. Assistência de ar na deposição e perdas de produtos fitossanitários em pulverizações na cultura da soja. Scientia Agricola, Piracicaba, v.57, n.2, p.271-276, 2000.

BLACK, R.J. Complexo soja fundamentos, situação atual e perspectivas. In: CÂMARA, G.M.S. soja: Tecnologia da produção II. ESALQ, Piracicaba - SP. 2000 1-17p.

BOLLER, W.; FORCELINI, C. A.; HOFFMANN, L. L. Tecnologia de aplicação de fungicidas - parte I. Revisão Anual de Patologia de Plantas, Passo Fundo, v. 15, p. 243-276, 2007.

BUENO, M. R.; CUNHA, J. P. A. R.; ALVES, G. S. Estudo do espectro de gotas produzidas nas pulverizações aérea e terrestre na cultura da batata. Revista de Ciências Agrárias, Belém, v. 54, n. 3, p. 225-234, 2011. 
BUTZEN, S.; MARCON, A.; MCINNES, B.; SCHUH, W. Asian soybean rust: fungicide application technology. Crop Insights, Johnston, v. 15, n. 1, p. 1-6, 2005.

CÂMARA, G.M.S. Introdução ao agronegócio da soja. ESALQ, LPV, 2015. 30 p.

CÂMARA, G.M.S. soja: Tecnologia da produção II. ESALQ, Piracicaba - SP. 2000 1-17p.

CHECHETTO, R. G.; ANTUNIASSI, U. R.; MOTA, A. A. B.; CARVALHO, F. K.; SILVA, A. C. A.; VILELA, C. M. Influência de pontas de pulverização e adjuvantes no potencial de redução de deriva em túnel de vento. Semina: Ciências Agrárias, Londrina, v. 34, n. 1, p. 37 46, jan./fev. 2013.

CHRISTOFOLETTI, J. C. Considerações sobre a deriva nas pulverizações agrícolas e seu controle. São Paulo: Teejet South América, 1999. 15 p.

CONAB - Companhia Nacional de Abastecimento. Boletim da safra de grãos, Safra: 2018/19. Décimo levantamento, Brasília, v.6, n.10, 49p, 2019.

COSTA, A.G.F. et al. Determinação da deriva de 2,4-D e glyphosate com diferentes pontas de pulverização e adjuvantes. In: CONGRESO de la ASOCIACIÓN LATINO-AMERICANA DE MALEZAS, 28., 2008, Ouro Preto, MG. Anais... Sete Lagoas: SBCPD / Embrapa Milho e Sorgo, 2008.

COSTA, A.G.F. et al. Adjuvantes na deriva de 2,4-D + glyphosate em condições de campo. Ciência Rural, Santa Maria, v.44, n.3, p.387-392, 2014.

CUNHA, J.P.A.R.; RUAS, R.A.A. Uniformidade de distribuição volumétrica de pontas de pulverização de jato plano duplo com indução de ar. Pesquisa Agropecuária Tropical, Goiânia, v.36, p.61- 66, 2006.

CUNHA, J. P. A. R.; ALVES, G. S. Características físico-químicas de soluções aquosas com adjuvantes de uso agrícola. Interciência, v. 34, n. 9, p. 655-659, 2009.

CUNHA, J. P. A. R.; PERES, T. C. M. Influência de pontas de pulverização e adjuvante no controle químico da ferrugem asiática da soja. Acta Scientiarum. Agronomy, Maringá, v. 32, n. 4, p. 597-602, 2010.

CUNHA, J. P. A. R.; JULIATTI, F. C. REIS, E. F. Tecnologia de aplicação de fungicida no controle da ferrugem asiática da soja: resultados de oito anos de estudos em minas gerais e goiás. Bioscience jornal, v. 30, n. 4, p. 950-957, 2014.

DE MORI, C.; COSTAMILAN, L. M. Ferrugem de soja: estimativas de custo de controle, em Passo Fundo, RS. Passo Fundo: Embrapa Trigo, 2004. 10 p. Embrapa Trigo. Documentos Online; 32. Disponível em: <http://www.cnpt.embrapa.br/biblio/do/p_do32.htm> Acesso em: $12 / 04 / 2019$. 
DURIGAN, J. C.; CORREIA, N.B. Efeitos de adjuvantes na aplicação e eficácia de herbicidas. In: VARGAS. L.; ROMAN, E. S. Manual de manejo e controle de plantas daninhas. Passo Fundo: Embrapa Trigo, 2008. p. 133-171.

EMBRAPA. [2015]. Software gotas. Disponível em: <http://www.cnpma.embrapa.br/novidades/soft_gota.html> Acesso em: 26/06/2019

FELSOT, A.S. et al. Agrochemical spray drift; an assessment and mitigation - A review. Journal of Environmental Science and Health Part B - Pesticide Food Contaminants and Agricultural Wastes, v.46, n.1, p.1-23, 2010. Disponível em: <http://www.ncbi.nlm.nih.gov/pubmed/20981606> Acesso em: 25/05/2019.

GENT, D. H.; SCHWARTZ, H. F.; NISSEN, S.J. Effect of commercial adjuvants on vegetable crop fungicide coverage, absorpition, and efficacy. Plant Disease, v.87, n.5, p.591-597, 2003.

GREEN, J. M. Adjuvants outlook for pesticides. Pesticide Outlook, Cambridge, p. 196-199. 2000 .

HAZEN, J. L. Adjuvants: terminology, classification, and chemistry. Weed Technology, Champaign, v. 14, p. 773-784, 2000.

JOHNSON, A.K. et al. Glyphosate spray drift management with drift reducing nozzles and adjuvants. Weed Technology, v.20, p.893-897, 2006. Disponível em: <http://www.bioone.org/doi/abs/10.1614/WT-05-162.1>. Acesso em: 27/05/2019. doi:10.1614/WT-05-162.1.

JUNIOR, J.D.G; JÚNIOR, J.M.S.; GONTIJO, G.A.; RUAS, R.A.A. Pontas hidráulicas, adjuvante e horários de aplicação de fomesafen no controle de picão-preto. Revista Brasileira de Herbicidas, v.14, n.4, p.326-332, 2015.

JUNIOR, O.M.; Antuniassi, U. R. Construção e validação de um túnel de vento para ensaios de estimativa da deriva em pulverizações agrícolas. Revista Energia na Agricultura, v.26, p.118$136,2010$.

KISSMANN, K. G. Adjuvantes para caldas de produtos fitossanitários. In: GUEDES, J. V. C.; DORNELLES, S. B. Tecnologia e segurança na aplicação de agrotóxicos. Santa Maria: Departamento de Defesa Fitossanitária, Sociedade de Agronomia de Santa Maria, 1998. p. 3951.

$\mathrm{KOCH}, \mathrm{H}$. The evolution of application techniques in Europe. In: SIMPÓSIO INTERNACIONAL DE TECNOLOGIA DE APLICAÇÃO DE PRODUTOS FITOSSANITÁRIOS, 1. Águas de Lindóia. Anais... Jaboticabal: IAC; UNESP, 1997. p. 3038 .

MATUO, T. Desenvolvimento de um pulverizador intermitente operado fotoeletricamente para tratamento de pomares de citros. 1988. 167 f. Tese (Livre-Docência) - Universidade Estadual Paulista, Faculdade de Ciências Agrárias e Veterinárias, Jaboticabal, 1988. 
McMULLAN, P. M. Utility adjuvants. Weed Technology, Champaign, v. 14, p. 792-797, 2000.

MONTÓRIO, Gilmar A. et al. Eficiência dos surfatantes de uso agrícola na redução da tensão superficial. Revista Brasileira de Herbicidas, v. 4, n. 2, p. 8-22, 2005.

MOTA, A. A. B. Quantificação do ar incluído e espectro de gotas de pontas de pulverização em aplicação com adjuvantes. Botucatu, 2011. 63 p.

NUYTTENS, D.; DE SCHAMPHELEIRE, M.; BAETENS, K.; BRUSSELMAN, E.; DEKEYSER, D.; VERBOVEN, P. Drift from field crop sprayers using an integrated approach: results of a five-year study. Transactions of the ASABE, St. Joseph, v. 54, n. 2, p. 403-408, 2011.

OLIVEIRA, R.B. Caracterização funcional de adjuvantes em soluções aquosas. Botucatu, 2011. 134f. Tese (Doutorado em Agronomia). FCA/UNESP.

PIVONIA, S.; YANG, X. B. Assessment of the potential year-round establishment of soybean rust throughout the world. Plant Disease, Saint Paul, v. 88, n. 5, p. 523-529, 2004.

RAETANO, C.G. Assistência de ar em pulverizadores de barra. Departamento de produção vegetal, Defesa fitossanitária, v.64, n.2, p.221-225, 2002.

RAMOS, H. H.; PIO, L. C. Conceitos básicos de aplicação de produtos fitossanitários. In: ZAMBOLINM, L.; CONCEIÇÃO, M. Z.; SANTIAGO, T. O que os engenheiros agrônomos devem saber para orientar o uso de produtos fitossanitários. Viçosa, 2008. p. 155-157.

REICHARD, D. L. et al. Spray droplet size distribuitions delivered by air blast orchard sprayers. Transactions of the ASAE, 20, n. N 2, 1977. 232-237.

RODRIGUES, J. D. Absorção e transporte de solutos nas plantas. In: VELINI, E. D. et al. Glyphosate. Botucatu: FEPAF, 2009. p.31-59.

RUPE, J.; SCONVERS, L. Soybean rust: The Plant Health Instructor. 2008. Disponível em: $<$ http://www.apsnet.org/edcenter/intropp/lessons/fungi/basidiomycetes/Pages/SoybeanRus t.aspx> Acesso em: 12/05/2019.

SANTOS, R.O. Níveis de deposição de produtos líquidos com aplicação aérea utilizando adjuvantes. 2007. 83 f. Dissertação (Mestrado em Máquinas e Automação Agrícola) Universidade Federal de Lavras, Lavras, 2007.

SARTORI, S. Equipamentos tratorizados para culturas de baixo fuste: situação no Cone-Sul. In: SIMPÓSIO INTERNACIONAL DE TECNOLOGIA DE APLICAÇÃO DE PRODUTOS FITOSSANITÁRIOS, 1., 1996, Águas de Lindóia. Anais. Jaboticabal: 1997. p.110-112.

SCHERMA, H.; CHRISTIANO, R. S. C.; ESKER, P. D.; DEL PONTE, E. M.; GODOY, C. V. Quantitative review of fungicide efficacy trials for managing soybean rust in Brazil. Crop Protection, London, v. 28, n. 9, p. 774-782, 2009. 
SCUDELER, F. Assistência de ar e angulação da barra pulverizadora na deposição de perdas da pulverização na cultura da batata. Botucatu, Universidade Estadual Paulista "Júlio de Mesquita Filho" Faculdade de Ciências Agronômicas (Mestrado em Agronomia), 2005.

SEDIYAMA, T. Tecnologia de produção de sementes de soja. Londrina: Mecenas, 2013. $352 \mathrm{p}$.

SIKORA, E. J.; ALLEN, T. W.; WISE, K. A.; BERGSTROM, G. A Coordinated Effort to Manage Soybean Rust in North America: A Success Story in Soybean Disease Monitoring, Plant Disease, Saint Paul, v. 98, n. 7, p. 864-875, 2014.

TU, M.; CALliE, H.; RANDALl J.M. Weed Control Methods Handbook: Tools \& Techniques for Use in Natural Areas. The Nature Conservancy, 2001, p. 7-10.

USDA - UNITED STATES DEPARTMENT OF AGRICULTURE. Foreign Agricultural Services. Oilseeds: World markets and trade. Disponível em: <https://www.fas.usda.gov/data/oilseeds-world-markets-and-trade> Acesso em: 24 de maio, 2019.

VARGAS, L.; ROMAN, E. S. Conceitos e aplicações dos adjuvantes. Passo Fundo: Embrapa Trigo, 2006. 10 p. html. (Embrapa Trigo. Documentos Online, 56). Disponível em: <http://www.cnpt.embrapa.br/biblio/do/p_do56.htm> Acesso em: 21/06/2019.

VIANA, R.G.; FERREIRA, L. R.; FERREIRA, M.C.; TEIXEIRA, M.M.; ROSELL, J. R.; MACHADO, A.F.L. Distribuição volumétrica e espectro de gotas de pontas de pulverização de baixa deriva. Revista Planta Daninha,v. 28, n. 2, p. 439-446, 2010.

VILELA, C.M. EVAPORAÇÃO DE GOTAS DE CALDAS CONTENDO FUNGICIDAS E ADJUVANTES DEPOSITADAS EM SUPERFÍCIE. Botucatu: Faculdade de Ciências Agronômicas da UNESP, 2012. 73p. Dissertação (Mestrado em Agronomia) - Faculdade de Ciências Agronômicas da UNESP, 2012.

YORINORI, J.T.; LAZZAROTTO, J.J. Situação da ferrugem asiática da soja no Brasil e na América do Sul. Londrina:Embrapa Soja, 2004. 27p. (Embrapa Soja. Documentos, 236. Disponível em: <www.cnpso.embrapa.br/download/alerta/Documentos236.pdf.> Acesso em: 09/05/2019.

YU, Y.; ZHU, H.; OZKAN, H. E.; DERKSEN, R. C.; KRAUSE, C. R. Evaporation and deposition coverage area of droplets containing insecticides and spray additives on hydrophilic, hydrophobic, and crabapple leaf surfaces. Transactions of the ASABE, St. Joseph, v. 52, n. 1, p.39-49, 2009. 